\title{
Robotized system of GRC panels for construction industry
}

\author{
C.Balaguer, F.J.Rodríguez, J.M.Pastor, R.Aracil, A.Barrientos, E.A.Puente \\ J. Flórez", M. Esteban", J.A. Comas*, E. Márquez*
}

Div. Ingeniería de Sistemas y Automática (DISAM), Universidad Politécnica de Madrid, c/José Gutierrez Abascal, 2, Madrid 28006, Spain.

*Dragados y Construcciones, S.A., c/Orense, 81, Madrid 28020, Spain.

\begin{abstract}
This paper presents a robotized system that produces high quality GRC panels in an automatic way. The system is installed in a Dragados y Construcciones factory near Zaragoza. The input of the system are the 3D AUTOCAD drawings of the panels. The output of the system are the robots paths, which are generated automatically, and real-time optimum sequences of the system processes: robot movements, spray gun working, panels transportation and mortar preparation.
\end{abstract}

\section{INTRODUCTION}

The GRC (Glass Reinforced Cement) technology was developed through the last 30 years. The GRC panels can be design as wall units, windows wall units, columns, etc. [1]. The lightness of GRC material permits to perform very big panels $(4 \times 3 \mathrm{~m})$ easy to assembly in the site. However the GRC panels fabrication process is performed nowadays in a artisanal and manual way. Using this manual method adequate quality is a limiting factor in the production capability of GRC panel factories.

The manual process is performed using a conventional mortar spraying gun equipped with a glass fiber cutter. Two simultaneous shots, one of mortar and one of glass fiber, are directed on the panels. These shots are usually not concentric. Required thickness of the panel is obtained by progressive spraying and forming of $2-5 \mathrm{~mm}$ layers. Compactation by roller or trowel is necessary after each spraying. In this way several types of panels will be performed by the developed system: shell with and without isolation, sandwich and stud frame. Its minimum thickness is about $8 \mathrm{~mm}$.

The automatization of the spraying process will permit to increase the quality and uniformity of the panels, save an appreciate quantity of materials, and organize in a more efficient way the factory production. This is why the developed system is a very important step towards fully automated prefabricated system, like in the manufacturing industry [2]. 


\section{SYSTEMS STRUCTURE}

The scheme of the developed system is presented in Figure 1. It is formed by four subsystems: a) spraying cell based on the ASEAs 6DOF IRb-3200 robot, b) compacting cell based on four manual workplaces (in the future will be automatic), c) roller based transportation system for panels, and d) mortar preparation cell. Each of the sub-systems has its own control system which are coordinated by the main computer.

The spraying cell is the main sub-system. It is presented in the Figure 2 and is formed by the robot, the spraying workplace, and the electronic pump spray station. The position of the robot is selected in order to spray panels of maximum dimensions: $3 \times 4 \mathrm{~m}$. The robot is equipped in its tip with the concentrical spraying gun. The maximum and minimum productivity of the gun are 36 and $18 \mathrm{~kg} / \mathrm{min}$ respectively. The mortar and the glass fiber (three separate wires sets) reach the robots tip in such way that no interferences take place during its movement. This restriction strongly influences in the joints path planning.

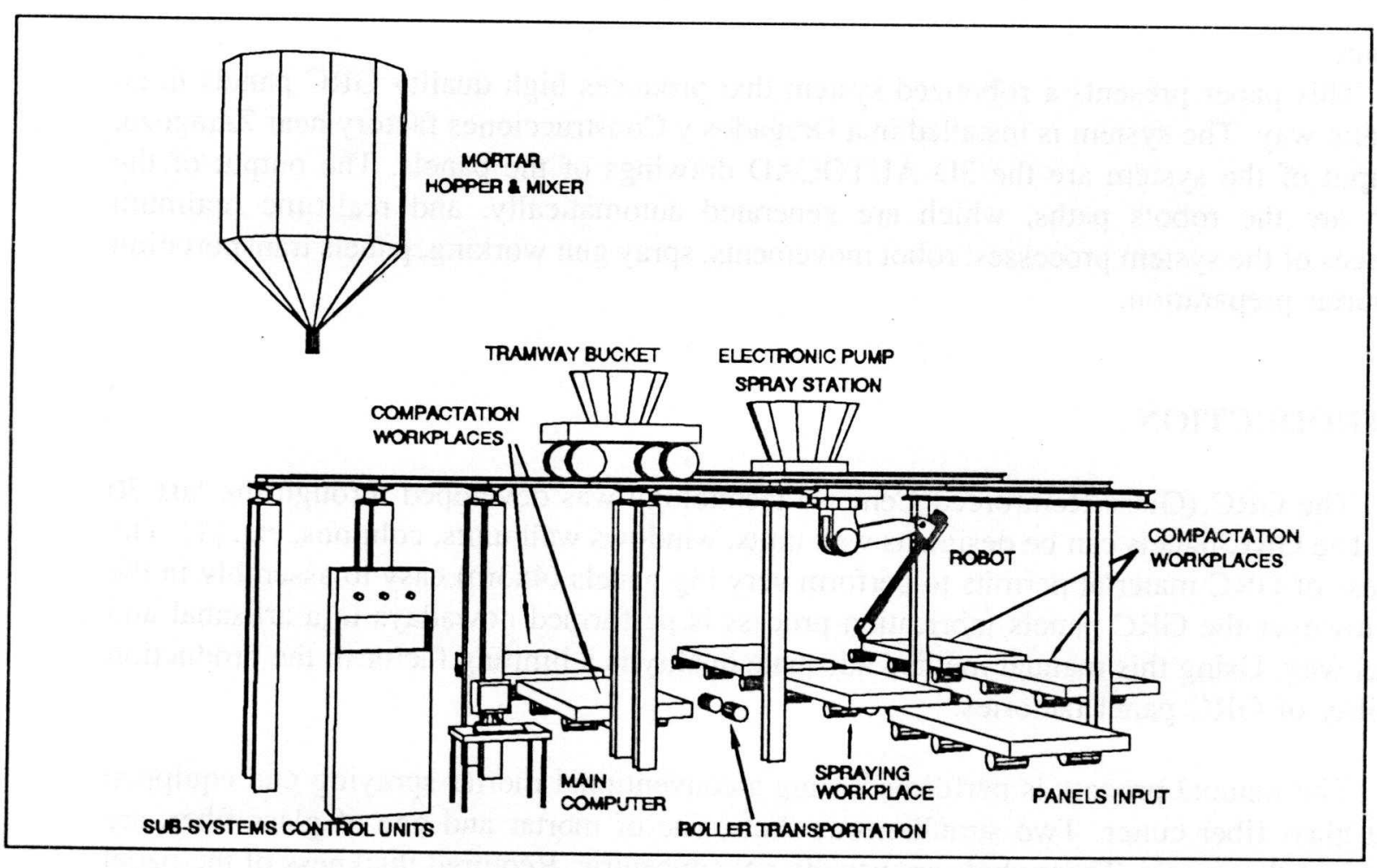

Figure 1. Systems structure scheme.

The sparying workplace is omnidirectional. The panels reach this workplace from every other workplace of the system using roller transportation. The level of the mortar in the electronic pump and the possibility of being the fiber unexpectedly cut are controlled automatically. If this happenes the robot automatically stops and moves to a previous programmed position in order to repair this abnormal situation. 
The compactation cell is formed by four workplaces which are manual ones in this stage of the project. But in the near future they will. be robotized in the same way that the spraying workplace is. In order to optimize the productivity of the system main computer plans in real-time the most adequate place for panel transportation. In order to know when and where the human operators are to start and had finish the concurrent compactation processes, several indicators and switches are situated near the compactation workplaces.

The input and output of the panels are performed in a manual way using the conventional crane. The instant and the type of panels to input or output are assisted by the main computer using display.

The transportation of the mortar from the hopper\&mixer to the electronic pump spray station is performed in an automatic way using a tramway

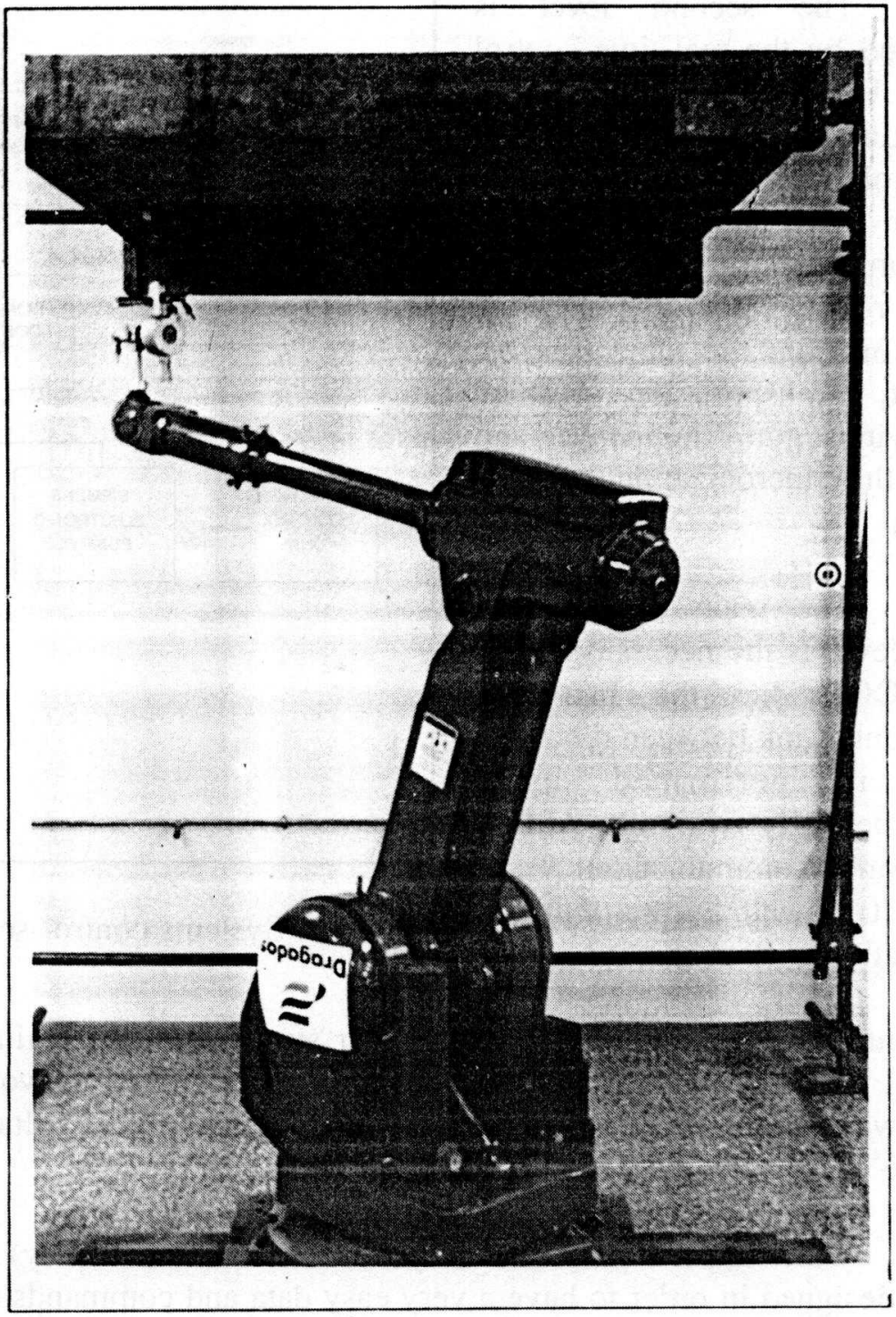

Figure 2. Spraying cell. bucket.

\section{CONTROL SYSTEM}

The control system is based on the distributed and hierarchical concept. There are three main levels in the control system. The main computer, which is situated in the second level, coordinates all the sub-systems control units and performs the man-machine interface. The structure of the control system is presented in the Figure 3. The high level control is for offline programming. It is based on a powerful PC where AUTOCAD version 12 and specially developed software run. The input of this level are the drawings of the several layers of the panels, type of materials and clamps, position of isolation materials, etc. The output is the robots path. 
The second level is formed by the real-time control PC. Its main mission is to coordinate the sub-systems control units. The input is the order list of panels to be performed during the day and their robots paths. The output is the commands to the processes: robot, transportation system, spraying gun, hopper\&mixer, and the sincronization between them.

The main difficulty of this level is the necessity to use MS-DOS due the fact that computer link between robot and $\mathrm{PC}$ is performed using commercially available ASEAs software Communication Tools [3]. It is well known that this operating system is not for real-

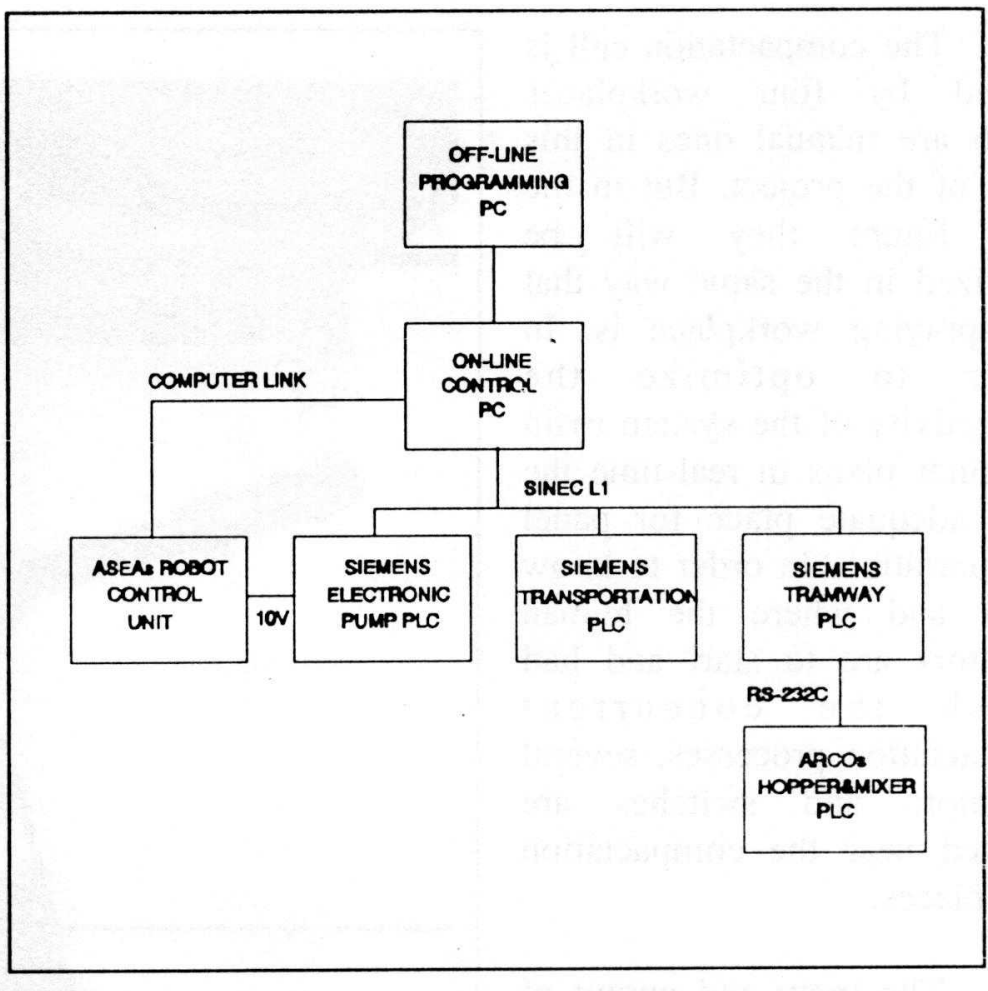

Figure 3. Systems control scheme. time applications. But its advantage is the hardware low cost. Our system has two main input/output channels: robot serial line and SIEMENS network SINEC L1. For the network communications speciai a hardware with a big buffers is used. In this order the simultaneous communications don't cause any problems to the systems.

Other important channel (keyboard, mouse and display) is the man-machine interface. It is designed in order to have a very easy data and commands exchange between the system and the human operator. An example of the man-machine interface during the real-time control is presented in the Figure 4. Other important feature is the very fast response, specially during emergency stop of the system. The sample period of the control loop is in average about $200 \mathrm{msec}$.

The on-line control PC has others secondary off-line missions: one day panels production planning, optimum ordering of the planned panels, data login, maintenance, manual (step-by-step) control of the system, etc.

The third level of the control system is formed by the robot control unit and four PLCs. Each of them is responsible for one of the system processes. There are no connections between PLC, except the connection between robot and pump. This is an $+-10 \mathrm{~V}$ analog channel. It is used to coordinate the robots velocity, and the guns mortar and fiber flows. Without this space and time sincronization the high quality of the GRC spraying layer is not possible. 


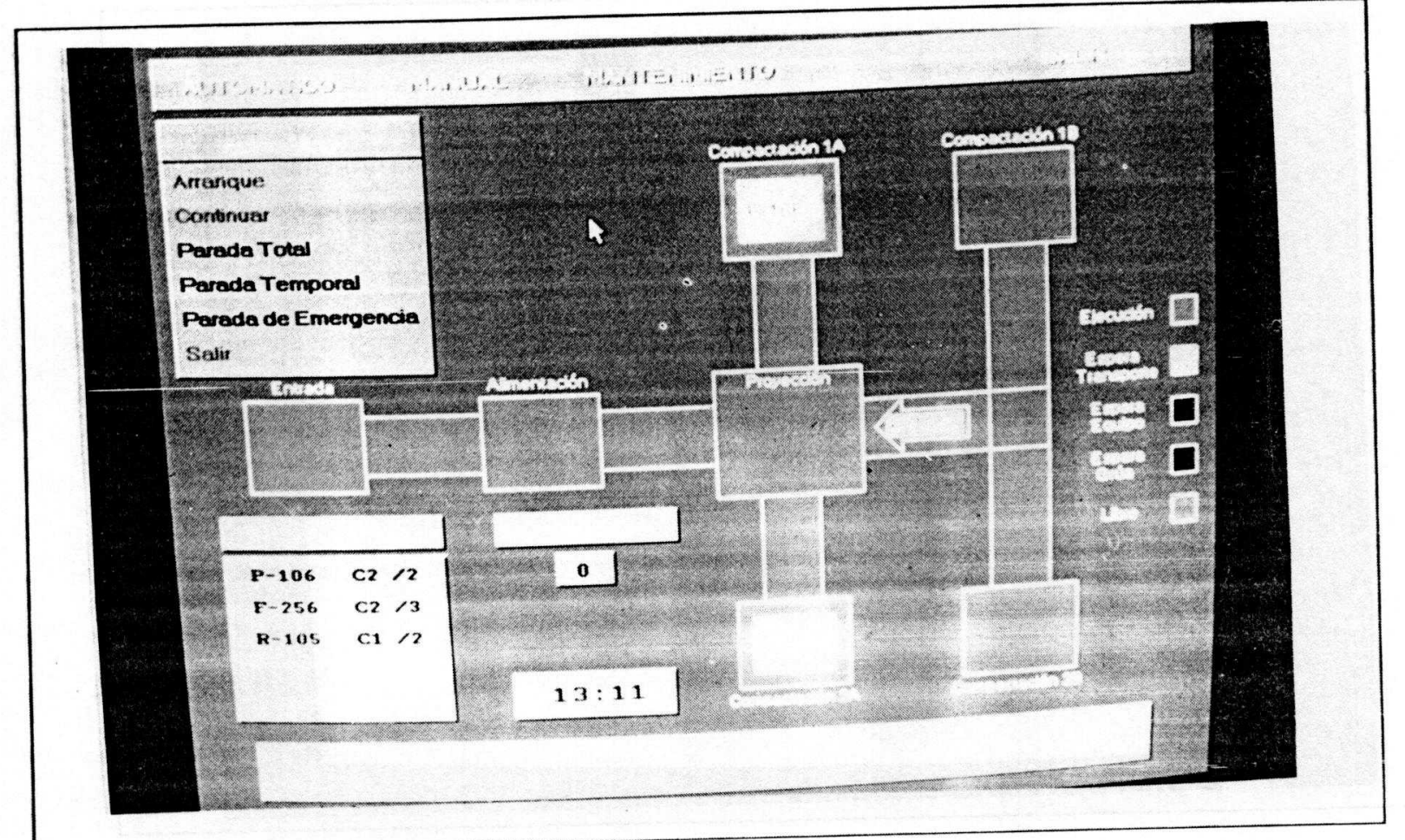

Figure 4. Man-machine interface.

\section{PANELS DEFINITION AND ROBOTS PATH PLANNING}

One of the best advantages of the system is the automatic robot path planning from 3D AUTOCAD v12 panels drawings. The 3D AME v2.0 software [4] has been used and linked with specially developed $\mathrm{C}$ software.

The drawings of the panels are performed through an GRC menu which helps the human operator to draw the panel layer by layer and introduce the following information for each layer (see Figure 5):

- type of the layer (bottom or side),

- type of the layers material (with or without fiber, mortar type, etc.),

- thickness of the layer,

- type and position of isolators and clamps,

- cone of the spraying gun,

- etc. 


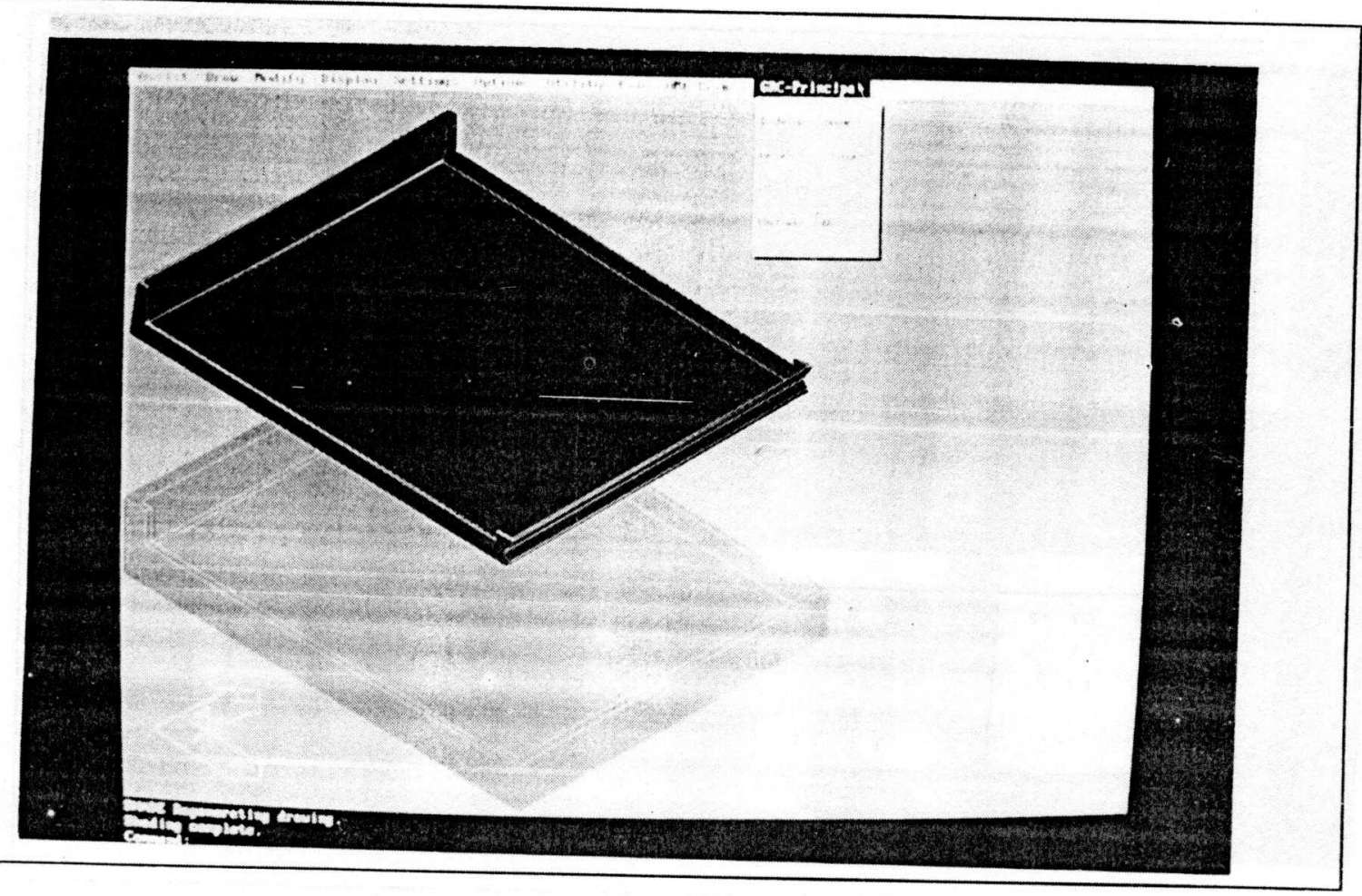

Figure 5. Panel definition through CAD system.

Other parameters like distance of projection, and very specially orientation of the spraying gun and robots path are generated automatically. There are four steps:

1) Computation of the $3 \mathrm{D}$ convex volumes and its conectivities which represent all "free" space between this layer and the previous one. For this purpose we extrusioned the previous layer and cut it by planes or by normalized revolution surfaces of the borders. This is why only panels with any number of planes and revolute permits are possible. Developed algorithm is similar to Dobkins one [5].

2) Computation of the robots position and orientation in such way that no collisions occurs between the robot with the spraying gun and the panels, and the robot and the gun. For this purpose several free-collision path planning algorithms have been used,
like [6].

3) Computation of the robots path in order to obtaine continuous paths without stops or with minimum number of stops. This is a necessary condition in order to optimize the path. Used algorithm is based on the Hansens idea [7].

4) Modification of the robots path keeping in mind the robots joints limits (specially for the first axis), the limitation of the joints rotations during the movements in order to do not roll up the mortar and fiber tubes, the changes in the robots configuration to obtained smooth or spline paths, etc. 


\section{CONCLUSIONS}

The developed system presents a new step toward fully automatic prefabricated manufacturing. The quality of GRC panels and factory productivity are increased. But the most important advantage is the flexibility of the system in order to introduce new types of panels. This procedure has been done in very fast and easy way. It is assisted by the standard CAD system and is structured in order to be independent from systems lay-out and robots type.

\section{ACKNOWLEDGEMENTS}

This work is sponsored by construction company Dragados y Construcciones, S.A. and the Spanish Ministry of Industry. Special thanks to E. Pinto and L.F. Peñin for their developments. The subcontracted companies of this project are: ARCO Electrónica, S.A., ODEMSA, S.A. and SIEMENS, S.A. The assistance of MULTICAD is very appreciated.

\section{REFERENCES}

E.S.Knowles (editor), Recommended Practice for Glass Fiber Reinforced Concrete Panels, Prestressed Concrete Institute, 1987.

A.Barrientos, H.Amaris, A.Yela, R.Aracil, C.Balaguer, Control System for an Automatic and Intelligent Packing Cell, International Symposium on Robotics, Mechatronics and Manufacturing Systems (IMACS/SICE RM ${ }^{2} S$ ), Kobe (Japan), 1992.

3 Communication Tools User's Guide, ABB Robotics, 1991.

4 AUTOCAD AME 2.1 and API Reference Manual, Autodesk, Inc, 1992.

5 D.Dobkin, L.Guibas, J.Hershberger, J.Snoeyink, An Efficient Algorithm for Finding the CGS Representation of a Simple Polygon, Computer Graphics, vol.22, n⿳⺈, 1988. C.Balaguer, F.J.Rodrigues, J.M.Pastor, E.Gambao, R.Aracil, A.Barrientos, A Rule-base Selection of C-space representation for Rapid 3D Robot Path Planning, 7th IFAC/IFIP Symposium on Information Control Problems in Manufacturing (INCOM), Toronto (Canada), 1992.

A.Hansen, F.Arbab, An Algorithm for Generating NC Tools Paths for Arbitrary Shaped Pockets with Islands, ACM Transactions on Graphics, vol.2, n², 1992. 